cases polonium haloes can form in that manner: hundreds of such secondarily formed ${ }^{210} \mathrm{Po}$ haloes have been found ${ }^{2}$ in a uranium-rich coalified wood from the Colorado Plateau. Earlier, when uraniumbearing solutions interacted with the uncoalified wood, numerous sites were formed containing a variety of elements. Uranium haloes subsequently developed around uranium-rich sites and ${ }^{210} \mathrm{Po}$ haloes around $\mathrm{Pb}-\mathrm{Se}$ inclusions. The absence of ${ }^{214} \mathrm{Po}$ and ${ }^{218} \mathrm{Po}$ haloes means that even though the hydrothermal transport was high enough to permit the accumulation of ${ }^{210} \mathrm{Po}$ and ${ }^{210} \mathrm{~Pb}$ to form ${ }^{210}$ Po haloes, it was too low for many of the nuclides with shorter half lives- ${ }^{214} \mathrm{~Pb}$, ${ }^{214} \mathrm{Bi},{ }^{214} \mathrm{Po}$ and ${ }^{218} \mathrm{Po}$ - to accumulate before decay. Thus, the formation of ${ }^{214} \mathrm{Po}$ and ${ }^{218} \mathrm{Po}$ haloes was inhibited.

Acceptable as that explanation is as far as ${ }^{210} \mathrm{Po}$ haloes in coalified wood are concerned, there are formidable obstacles in using it to account for the variety and distribution of ${ }^{210} \mathrm{Po},{ }^{212} \mathrm{Po},{ }^{214} \mathrm{Po}$ haloes in minerals. Except along conduits or cracks where solutions have passed, atomic migration in minerals proceeds by diffusion. Since the r.m.s. distance, $x$, that an atom of diffusion coefficient, $D$, will migrate in time, $t$, is $x=(2 D t)^{1 / 2}$ and the maximum value of $D_{\mathrm{pb}}\left(\right.$ at $20^{\circ} \mathrm{C}$ ) in 7 different minerals ${ }^{3}$ is $10^{-18} \mathrm{~cm}^{2} \mathrm{~s}^{-1}$, a ${ }^{210} \mathrm{~Pb}$ atom (with a half life of $22 \mathrm{yr}$ ) would migrate, on average, about $10^{-5} \mathrm{~cm}$ before decay. Even at $1,038^{\circ} \mathrm{C}$ the $D_{\mathrm{Pb}}$ value $\left(10^{-11} \mathrm{~cm}^{2} \mathrm{~s}^{-1}\right)$ in microclinepertite ${ }^{3}$ yields negligible migration $(x=0.11 \mathrm{~cm})$ of a ${ }^{210} \mathrm{~Pb}$ atom before decay. Further, this is a somewhat unrealistic case, for even though shortened fission tracks exist in some micas ${ }^{4}$, the great majority of minerals containing polonium haloes show no evidence of high temperature episodes. Concerning Po haloes in fluorite I can be very specific. The $D_{\mathrm{Ba}}\left(\simeq D_{\mathrm{Pb}}\right)$ value is less than $10^{-22} \mathrm{~cm}^{2} \mathrm{~s}^{-1}$ at $300^{\circ} \mathrm{C}$ (ref. 5) and it is certain that the fluorite has not exceeded that temperature during or since halo formation, because halo coloration disappears within minutes in this temperature range ${ }^{6}$. In that case a ${ }^{210} \mathrm{~Pb}$ atom would migrate only about $10^{-7} \mathrm{~cm}$ before decay.

Thus, if $\mathrm{Po}$ or $\mathrm{Pb}$ radionuclides were migrating to Po halo radiocentres, most would have decayed in transit and produced a large excess of $\alpha$-recoil tracks close to the radiocentres, which is contrary to observation? ${ }^{7}$. An equally strong objection to the uranium-daughter hypothesis in uranium-poor (p.p.m. or less) minerals is that many Po haloes (such as the 'spectacle' halo) are located in the interior of large pegmatitic crystals as well as in small granitic mica flakes where they are often more than $10 \mathrm{~cm}$ and sometimes much less than $100 \mathrm{~cm}$ away from a significant uranium source. The fact that ${ }^{214} \mathrm{Po}$ and ${ }^{218} \mathrm{Po}$ haloes often occur profusely in some minerals $\left(10^{3}-5 \times 10^{4}\right.$ haloes $\mathrm{cm}^{-3}$ ), whereas their formation was inhibited even in the uranium-rich $16 \%$ U) coalified wood where nuclide transport rates were comparatively high, certainly suggests some other origin for polonium haloes in minerals.

But if isomers and uranium-daughter diffusion did not produce polonium haloes in rocks, we are left with the idea that polonium haloes originate with primordial Po atoms just as $\mathrm{U}$ and $\mathrm{Th}$ haloes originate with primordial ${ }^{238} \mathrm{U}$ and ${ }^{232} \mathrm{Th}$ atoms. Thus, a new type of $\mathrm{Pb}$ exists in polonium halo radiocentres, derived specifically from primordial polonium $\alpha$-decay. Carried to its ultimate conclusion, this means that polonium haloes, of which there are estimated to be more than $10^{15}$ in the Earth's basement granitic rocks ${ }^{8}$, represent evidence of extinct natural radioactivity, and thus imply only a brief period between 'nucleosynthesis' and crystallisation of the host rocks.

If this conclusion is considered highly improbable, then another explanation for the origin of the polonium should exist.

Research supported by Union Carbide Corporation and ERDA, and by Columbia Union College with an NSF grant.

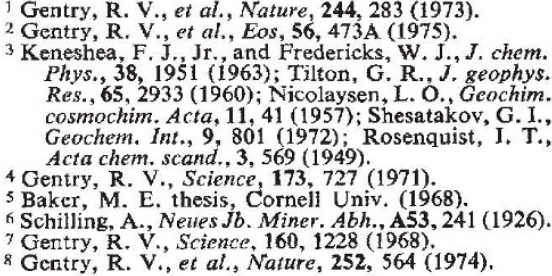

\section{Microorganisms on manganese nodules}

WE report here tubular forms found on the outer surface of a piece of coral coated with manganese from the eastern flank of the Mid-Atlantic Ridge (biotrawl at $747 \mathrm{~m}$, V22-D6 Lamont-Doherty Geological Observatory). Scanning electron microscopy (SEM) of a dark zone of the coral revealed well preserved coiled tubular fragments which may be Saccorhiza averaging $2-3 \mu \mathrm{m}$ in diameter (Fig. $1 a-d$ ). These tubular structures were not found on the inner surfaces. They are, however, ubiquitous throughout the dark ferromanganese zones on the outside of the manganese-coated coral. They seem merely to adhere or be cemented to zones rich in ferromanganese which show little distortion (Fig. $1 b-c$ ). We suggest that these organic structures are better preserved on fragments coated with ferromanganese than in the interior of compacted ferromanganese modules such as those studied by Greenslate ${ }^{\mathrm{I}}$.

\section{CARol M. Fredericks-Jantzen HeRBERT HeRMAN PATRICK HERLEY}

State University of New York, Stony Brook, New York 11794

I Greenslate, J., Nature, 249, 181-183 (1974).
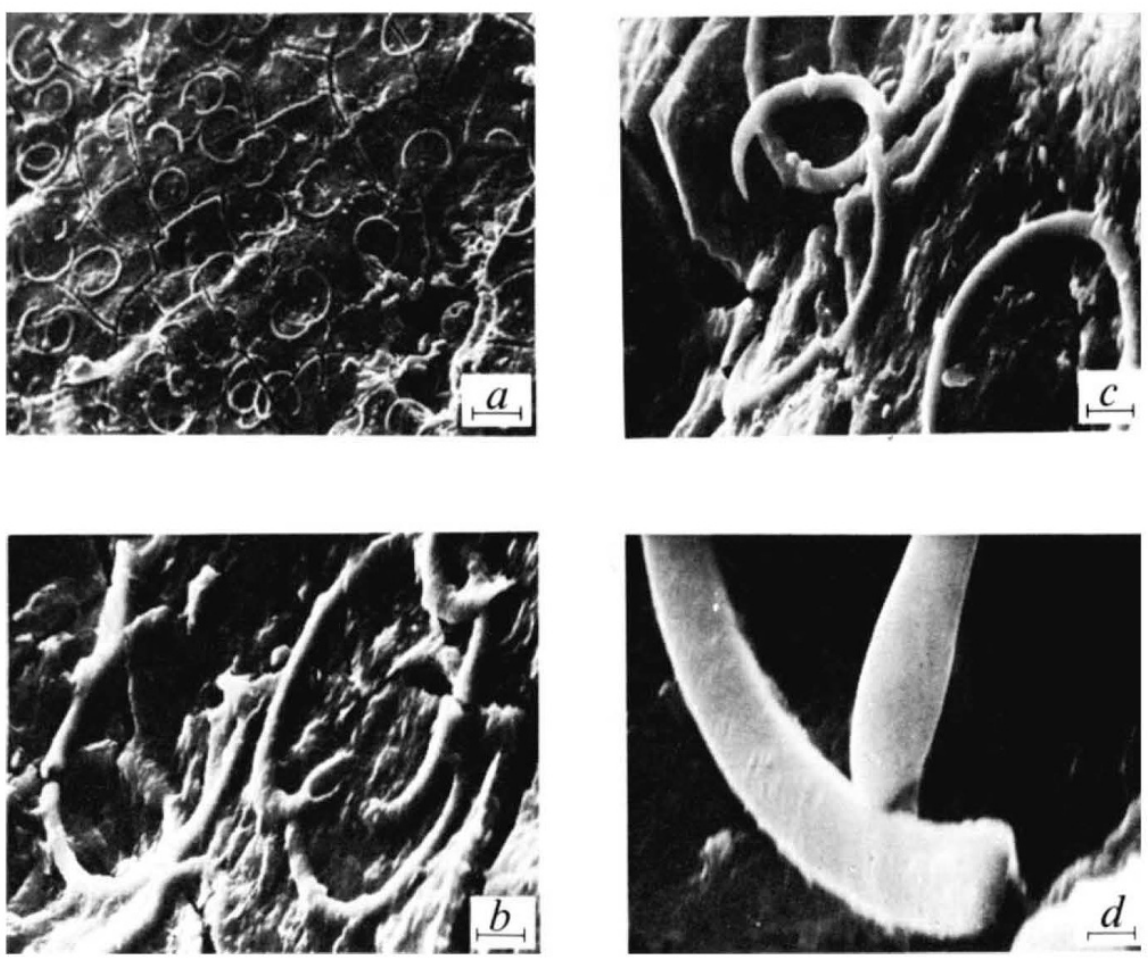

Fig. 1 $a$, SEM of the outside region of manganese-coated coral (V22-D6), showing circular, tubular structures (scale bar, $80 \mu \mathrm{m}$ ); $b$ and $c$, SEM of circular structures showing their adherence $(b)$ and cementation $(c)$ to the surface and their tubular nature (scale bar, $8 \mu \mathrm{m}) ; d$, SEM of tubular structures $2-3 \mu \mathrm{m}$ in size (scale bar, $1.6 \mu \mathrm{m}$ ). 